result by subcutaneous injection of essence of cloves into rabbits and guinea-pigs. Roger ${ }^{12}$ used a virulent culture of Friedländer's bacillus and produced in guinea-pigs engorgement and effusion into those glands. Talbot ${ }^{13}$ isolated from one case a streptococcus like pyogenes aureus but which differed from it in that it coagulated milk. Riesman ${ }^{14}$ found staphylococcus aureus and albus in pure culture from the blood and tissues of four cases.

Taking these data into consideration the possibility of a toxæmic origin becomes a probability but there are many difficulties. In the first place, it is surprising that in nearly every case in which bacteriological examination has been made the result proved negative. Then, again, in no case is there evidence of exposure to any source of infection, and furthermore, while profound toxæmia, the result of specific infection as in diphtheria and summer diarrhœa, is a common cause of death in children, cases of hæmorrhage into the suprarenals are very rare. If it be an infection presumably it is a special infection of unknown origin. I advance the crude state of our knowledge of this not unimportant condition as sufficient excuse for the publication of these additional cases.

London.

\section{FURTHER NOTE ON SOME ADDITIONAL POINTS IN CONNEXION WITH CHLOROFORMED CALF VACCINE. ${ }^{1}$}

\author{
By aLAN B. GReEN, M.A., M.D. Cantab. \\ (From the Government Lymph Laboratories.)
}

SINCE April, 1903, the date of my preliminary note ${ }^{2}$ on this subject, the preparation of calf vaccine by the chloroform process has been carried on at these laboratories and a large number of vaccines have now been treated by this method. These lymphs have been freed from their non-sporebearing extraneous bacteria within a period ranging between one and eight hours after their collection from the calf and have, subject to the usual tests, been issued for general vaccination purposes about two weeks after collection. Their use has resulted in high "case" and "insertion" success. The following points in connexion with these vaccines have been investigated.

The effect of temperature in the elimination of extraneous micro-organisms from orude calt vacoine by the chloroform process. - It has been ascertained that the temperature at which vaccine emulsion is subjected to the chloroform process determines largely the rate at which the extraneous bacteria of that emulsion are eliminated. This has been shown in two ways. In the first set of experiments vaccine emulsion consisting of one part by weight of pulp and two parts by weight of water was divided into several equal portions. Each portion was then submitted to a pre-determined and separate temperature along with the set of apparatus to be used for its treatment with chloroform. These temperatures ranged from $10^{\circ}$ to $37^{\circ} \mathrm{C}$. In each case after both emulsion and apparatus had reached the requisite tempezature of the experiment passage of chloroform vapour and air through the emulsion was effected. was found by means of plate cultivations that elimination of extraneous micro-organisms was most rapidly effected in the case of the emulsions chloroformed at $37^{\circ} \mathrm{C}$. and that elimination was most slowly effected in the case of the emulsions chloroformed at $10^{\circ} \mathrm{C}$. Between these temperatures the gradation of germicidal action was very constant. The potency of these vaccines was subsequently tested by inoculations on calves, with the result that vaccines which had been subjected to the chloroform process at temperatures below $30^{\circ} \mathrm{C}$. caused rather better vesiculation than the vaccines treated at temperatures above $30^{\circ} \mathrm{C}$. In the second set of experiments vaccine emulsion, prepared as before, was 12 Comptes Rendus des Séances de la Société de Biologie, January,
1894.

13 St. Bartholomew's Hospital Reports, 1900.

* Post-Mortem Reports, University Hospital, Philadelphia.

A paper read before the Royal Society on May 5th, 1904. Proceedings of the Royal Society, 1903, and THE LANCET,
June 20th, 1903, p. 1738 . divided into a number of equal portions, each of which was placed in a separate test-tube. In this case the emulsions were all subjected to the chloroform process at $15^{\circ} \mathrm{C}$. After the passage of chloroform vapour and air through the emulsions for half an hour, the entrance and exit of each vaccine tube were clamped in order that none of the contained chloroform might escape and the tubes were placed in temperatures ranging from $10^{\circ}$ to $37^{\circ} \mathrm{C}$. for 24 hours. In the case of these emulsions, where the amount of chloroform present in each must have been approximately the same, a similar gradation of germicidal action was evidenced as in the former set of experiments, elimination occurring most rapidly in the case of emulsions submitted to a temperature of $37^{\circ} \mathrm{C}$. and most slowly in the case of emulsions submitted to a temperature of $10^{\circ} \mathrm{C}$. The potency of each of these vaccine emulsions was tested as before by inoculations on calves, with the result that vaccines which had been submitted to temperatures below $30^{\circ} \mathrm{C}$. gave slightly better vesicles than vaccines which had been submitted to temperatures above $30^{\circ} \mathrm{C}$. Both series of experiments indicate that the temperatures at which extraneous bacteria are killed most quickly in vaccine emulsion by the chloroform process, the specific germ being left meanwhile in state of full activity, lie probably between $18^{\circ}$ and $23^{\circ} \mathrm{C}$

The species of micro-organisms lilled by the chloroform process. - In addition to the extraneous micro-organisms mentioned in the preliminary note as commonly occurring in crude calf vaccine and as being eliminated therefrom by means of chloroform experiments have been made with further species of bacteria. These, with the exception of the bacillus proteus valgaris and the bacillus coli communis, have never been found in vaccine lymph at these laboratories, but they have been subjected to the action of chloroform in order that knowledge of the germicidal value of that process might be extended. The bacteria thus experimented with are the bacillus proteus vulgaris, bacillus prodigiosus, bacillus pyocyaneus, bacillus flaorescens liquefaciens, bacillus coli communis, bacillus typhosus, bacillus diphtheriæ, bacillus mallei, bacillus pestis, bacillus tuberculosis, and spirillum choleræ Asiaticæ. Broth emulsions of these bacteria were first experimented with. As soon as an emulsion was established a suitable culture medium was inoculated with a small portion of it and duly incubated in order to ascertain whether the species of micro-organism in question could be easily recovered from the emulsion. The passage of chloroform vapour and air through the emnlsion was then begun and during the process at regular intervals further cultivations were made from it. In every instance the bacteria of experiment were found to have been killed at intervals ranging from one to eight hours from the commencement of the process. In a second set of experiments vaccine emulsions were prepared by mixing one part by weight of pulp with two parts by weight of water. To these emulsions the bacteria to be experimented with were added and cultivations were at once made therefrom in each instance to ascertain whether recovery of the bacteria was possible. Passage of chloroform vapour and air through the emulsions was then carried out and further cultivations were made from them from time to time. As in the case of the broth emulsions, after the passage of the chloroform vapour and air for a few hours the bacteria in the vaccine emulsions were killed. In the case of each experiment of the two foregoing series a "control " prepara. tion was established in which the bacteria were found to be still alive after the bacteria of the corresponding experimental preparation had been killed. The vaccine used in these experiments was collected for experimental purposes only

The keeping properties of chloroformed naccines.- The keeping properties of chloroformed vaccines have been tested in the following ways. First, vaccine lymph freshly collected from the calf was divided into two portions. One portion after emulsification with water was subjected to the chloroform process and after elimination of its extraneous micro-organisms the chloroform was partly removed by the passage through the emulsion of a stream of sterile air The other portion was emulsified with 50 per cent. of glycerine and water solution. These chloroformed and glycerinated emulsions were, within 24 hours of their collection from the calf, each subdivided into five parts, one part of each being stored at $10^{\circ}, 20^{\circ}, 25^{\circ}, 30^{\circ}$, and $37^{\circ} \mathrm{C}$. The potency of these several parts was subsequently tested on calves at regular intervals of time. The result showed (a) that the highest potency was retained for the longest time, alike for the chloroformed and glycerinated portions, by the 
emulsions stored at $10^{\circ} \mathrm{C}$., for the shortest time, alike again by both portions, by emulsions stored at $37^{\circ} \mathrm{C}$.; and (b) that the potency as between the chloroformed and glycerinated vaccine kept at any one of the foregoing temperatures was practically the same, the only marked difference occurring in case of the vaccines kept at $37^{\circ} \mathrm{C}$, a temperature at which the chloroformed emulsions retained potency for a longer period than did the glycerinated emulsions.

Upon the completion of the foregoing experiments, a further number of vaccines collected from vesicles of good average quality were emulsified with water in the proportion of one part by weight of pulp to two parts by weight of water, and subjected as before to the chloroform process. When elimination of their extraneous bacteria had been effected part of the chloroform was removed from the emulsions and these were placed in the ice-chest at $10^{\circ} \mathrm{C}$. Immediately prior to the issue of these vaccines the remainder of the chloroform was removed and glycerine was added in the proportion of two parts by weight of glycerine to the original weight of vaccine pulp. These vaccines were later, after passing the requisite tests, issued for general vaccinating purposes, a similar interval being allowed to elapse between their collection from the calf and subsequent issue as is usual at these laboratories in the case of glycerinated vaccine-namely, about six weeks. In the case of two of these chloroformed vaccines an interval of two months elapsed between collection and issue. The use of these chloroformed vaccines has been attended with results showing high "case" and "insertion" success.

Summary. - Experience of the further use of the chloroform process in the preparation of a large number of vaccines during the past year confirms the conclusions arrived at in the preliminary note. And meanwhile important additional knowledge has been gained-namely, that chloroformed calf vaccine, if originally of sufficiently high potency, will, when prepared and stored under suitable conditions, retain for a considerable time a high degree of potency and this notwithstanding that the extraneous organisms had been rapidly eliminated from it in an early stage of its preparation.

\section{WOUND OF THE LEFT THORAX, WITH EXTENSIVE LACERATION OF THE PLEURA, ETC.}

BY E. WYNSTONE-WATERS.

ON March 20th, at about 2.30 A.M., I was awakened by the arrival of a number of natives at $m y$ house and $I$ soon discovered that one of them, a man of about 25 years of age, had received a severe wound with a native knife. The wound occupied the left ninth intercostal space, its direction being oblique and parallel to the ninth rib, and extended posteriorly somewhat beyond the posterior axillary line, while in front it reached the anterior axillary line. The wound implicated the parietal pleura in nearly its whole length, except posteriorly where the incision became more superficial. The visceral pleura was also implicated, but to a less extent, and the lung tissue was lacerated. At the time I made the examination there were very considerable hæmorrhage and at first a marked whistling sound which, however, soon became indistinct. Pneumothorax was established, air having rushed in and separated the parietal and visceral pleura, and the lung was somewhat collapsed in virtue of its elasticity.

The wound having been thoroughly cleansed I did not attempt to reduce its size, thus being certain of a more efficient drainage and at the same time obtaining a larger field for observation. On the next day on removing the dressings I found that a considerable amount of hrmorrhage had occurred, while the external aperture was filled by a closely fitting plug of lung tissue which protruded somewhat beyond the external surface. No attempt was made to reduce this protrusion but it was kept thoroughly aseptic. The protruded lung was quite healthy and showed considerable crepitation due to the residual air. On the fourth day slight but steady pressure was applied to the protruded lung tissue and a firm compress of carbolic tow was strapped over the part. On the fifth day on removing the dressings I found that the lung tissue had yielded to the continued pressure of the compress and was inside the thoracic cavity. Shortly after this granulations were seen to be rapidly springing up all round. The area at first occupied by the plug of lung now presented a pink field of healthy newly formed tissue, only a very slight amount of pus being present on the dressings. The wound was kept plugged with cyanide gauze, so that the cavity was filled with healthy tissue from the very bottom, there being no opportunity for the development of any sinuses or other false cavities. Skin gradually spread from the edges of the wound and was soon seen to cover up the whole site of the lesion, except where a few exuberant granulations prevented its further encroachment. These islands of new tissue, however, soon yielded to a few touches from a crystal of blue stone and the skin rapidly covered up. their original site.

This case is one of exceeding interest to the physiologist as well as to the pathologist and surgeon, showing nature in one of her happiest moods. The patient belongs to the Waswahili, a subdivision of the Bantu section of the African negro, a race occupying a "thin line along a thousand miles of creeks and islands" on the East coast of Africa. The protruding portion of lung by its constant pressure caused inflammatory adhesion to take place between the visceral and parietal pleura along the line of pressure, thus completely sealing ap the rent into the pleural cavity and establishing a continuity of parietal and visceral pleura-in fact, producing a condition resembling the normal pleura-viz., a closed sac. The air in this now closed sac becoming rapidly absorbed, the lung expanded and the parietal and visceral layers of the pleura coming into apposition the normal process of respiration was again established. Doubtless in time the inflammatory adhesion of the pleura at the peripheral margin will become fibrous and the exposed surface of lung, which has been forced to retire within its own cavity, will adhere and become united by fibrous tissue to the scar tissue filling the original wound. Thus, by a perfectly natural process, aided by strictly antiseptic precautions, an exceedingly severe and dangerous wound was closed, the only drawback or compensation nature will impose being a somewhat diminished "vital capacity" on the affected side.

Lamu, British Fast Africa, May, 1904.

\section{GYNACOMASTIA.}

By EDWIN S. CRISPIN, M.R.C.S. ENG., L.R.C.P. LOND., CIVIL SURGEON AND HON. BIMBASHI, EGYPTIAN ARMY.

I READ with interest the article on Gynæcomastia in THE LANCET of March 26th, p. 865, by my colleagues, $\mathrm{Mr}$. A. Webb Jones and Dr. J. B. Christopherson as I happened to be at Merowi when I received that number of THE LANCET where Case 1 is still at work and where also $I$ found a third case. I regret that I was unable to get a photograph of the latter as $I$ had not my camera with me; he has a distinct gland in each breast of the size of a small Tangerine orange which can be easily moved over the muscles of the chest the nipples are also well developed. He also is a Sudanese, a Nubawi, Case 1 being a Furawi, not a Firtitawi, as mentioned in that article, but, howerer, they all come from the neigbbourhood of Darfur.

I believe that gynæcomastia is not at all an uncommon condition amongst the Sudanese of Central Africa. I saw two or three more cases amongst the Dinkas and Baris while I was travelling on the Bahr-el-Ghebel between Lake No and Gondokoro. Sir Harry Johnston in his book, "British Central Africa," gives a very good reproduction of a photograph of a similar case on p. 399 and says it is very common amongst Sudanese. I do not think that he can have confused these cases with those of prominent pectoral development of fat and muscle, as a digital examination would at once settle the diagnosis, but in a photograph these cases are very similar. I inclose a photograph taken by Dr. J. Warnock of the Egyptian Asylum, of a case of this latter sort, the 